\title{
ENTRAVES E PERSPECTIVAS À ORIENTAÇÃO DE TRABALHO DE CONCLUSÃO DE CURSO NA EDUCAÇÃO A DISTÂNCIA
}

\author{
Francisco Ricardo Miranda Pinto* \\ Stela Lopes Soares ${ }^{* *}$ \\ Carlos Antonio Bruno da Silva ${ }^{* * *}$
}

\begin{abstract}
Resumo: Aborda-se como núcleos centrais a Educação à Distância $(\mathrm{EaD})$ e a produção do Trabalho de Conclusão de Curso (TCC) nesta modalidade de ensino. O objetivo é refletir acerca dos entraves e perspectivas da orientação de TCC na EaD embasado na Pedagogia da Autonomia de Paulo Freire (1996). É um estudo de abordagem qualitativa, do tipo estudo de caso crítico-reflexivo realizado em Instituição de Ensino Superior (IES) da zona norte do Estado do Ceará. Percebe-se que as dificuldades neste formato são de origens diversas e que requerem do professor-orientador competências e habilidades para dinamizar os entraves sem que haja prejuízos ao acadêmico e à pesquisa. Considera-se a necessidade de efetivar maior rigor na produção técnica ao longo do curso no sentido de preparar o acadêmico ao processo de construção do TCC.
\end{abstract}

Palavras-Chave: Orientação. Professor-Orientador. Educação a Distância.

\section{BARRERAS Y PERSPECTIVAS PARA ORIENTACIÓN DE PROYECTO FINAL DE CURSO NA EDUCACIÓN A LA DISTANCIA}

Resúmen: El enfoque está en la Educación a distancia $(\mathrm{EaD})$ y la producción del proyecto final de curso (TCC) en esta modalidad. El objetivo es reflexionar sobre los obstáculos y las perspectivas de la orientación del TCC en el EaD basado en la Pedagogía de la Autonomía de Paulo Freire (1996). Es un estudio de abordaje cualitativo, del tipo estudio de caso crítico-reflexivo realizado en Institución de Enseñanza Superior (IES) de la zona norte del Estado de Ceará. Se comprueba que las dificuldades son de varios orígenes y que requieren habilidades del profesor orientador para dinamizar los obstáculos sin ningún daño a los académicos y la investigación. Se considera que es necesario que la técnica de producción sea más rigurosa en el momento en el que se prepare el juego para el proceso de construcción del TCC.

Palabras-Claves: Orientaciones. Profesor-Asesor. Educación a Distancia

Submissão 26-08-18 Aceite 12-12-18

\section{INTRODUÇÃO}

O presente estudo traz como temática central a orientação de Trabalho de Conclusão de Curso (TCC) na modalidade de Educação a Distância (EaD) na perspectiva de uma formação que não ocorre no espaço físico da sala de aula como na modalidade de ensino presencial. A pesquisa se justifica a partir da experiência vivenciada com o serviço de tutoria-orientação de TCC na $\mathrm{EaD}$ e as diferentes realidades encontradas no acompanhamento de acadêmicos nesta fase de escrita, logo

\footnotetext{
* Doutorando em Saúde Coletiva, Mestre em Saúde Coletiva, Especialista em Educação Pobreza e Desigualdade Social, Especialista em Coordenação Pedagógica, Especialista em Psicopedagogia, Bacharel em Enfermagem, Licenciado em Letras Português/Espanhol, Licenciado em Pedagogia. Docente do Curso de Pedagogia EaD do Centro Universitário INTA. Docente do Curso de Pedagogia da Universidade Estadual Vale do Acaraú.

*** Mestre em Ensino da Saúde; Graduada em Educação Física; Docente do Curso de Educação Física do Centro Universitário INTA - UNINTA.

**** Doutor em Ciências da Saúde; Mestre em Medicina (Clínica Médica); Graduado em Medicina; Docente da Universidade de Fortaleza.
} 
se apresenta relevante por corroborar com a literatura da área que tem buscado evidenciar a orientação de TCC na modalidade EaD.

A partir da justificativa emergem duas perguntas que norteia o estudo: Qual os entraves e perspectivas na produção do Trabalho de Conclusão de Curso na Educação a Distância? Quais os papeis dos protagonistas, orientador e orientando, na produção do Trabalho de Conclusão de Curso na Educação a Distância? Tem como Referencial Teórico a Pedagogia da Autonomia de Paulo Freire e literaturas pertinentes que apontam expertise na historicidade da $\mathrm{EaD}$ e nos diversos elementos que envolvem o trabalho no AVA e os papéis de orientador e orientando como Carvalho (2013), Hack (2011), Litto e Formiga (2009), ABED (2014; 2015; 2017) e outros. É um estudo de abordagem qualitativa, do tipo estudo de caso descritivo e crítico-reflexivo desenvolvido na Instituição A - nome fictício - tendo como lócus o Curso de Pedagogia EaD daquela instituição com acadêmicos em processo de construção do TCC. Os dados foram coletados a partir do acompanhamento do Projeto Político Pedagógico de Curso (PPC) e dos registros de orientação via AVA que se constitui o corpus de análise e os resultados são apresentados de forma descritiva com discussão à luz dos pressupostos da Pedagogia da Autonomia de Paulo Freire e literatura pertinente.

Os primeiros resultados apontam como entraves as dificuldades de manuseio das tecnologias o que compromete a comunicação entre os dois polos - orientador e orientando - entretanto tem como perspectiva a possibilidade do uso de outras ferramentas e estratégias que possam favorecer o contato virtual entre os atores do processo. O objetivo geral é depreender quais os entraves e perspectivas da orientação de Trabalho de Conclusão de Curso na modalidade Educação a Distância.

\section{EDUCAÇÃO A DISTÂNCIA: CONTEXTUALIZANDO ATORES E ATRIBUIÇÕES}

A Educação a Distância é o processo de ensino/aprendizagem, mediado pelas tecnologias, principalmente as telemáticas, o celular, computador, o rádio, a televisão, o vídeo, e/ou tecnologias semelhantes, cujo suporte é a internet, uma vez que professores e alunos estão distantes espacial ou temporalmente (MORIN, 2009; BRASIL, 2017).

O nascimento da EaD no Brasil remota a primeira metade do Século XX (décadas de 1920-30) com as ações de cunho particular desenvolvidas pela fundação do Instituto Radiotécnico Monitor, seguido pela Rádio Sociedade, pelo Instituto Universal Brasileiro (IUB), assim como pelo Instituto Padre Reus. Nos anos finais daquele mesmo século o 
IUB tem importante ascensão seguida de seu declínio com o falecimento de seu fundador e a decisão de não permanência dos trabalhos (CARVALHO, 2013).

$\mathrm{O}$ reconhecimento legislativo da $\mathrm{EaD}$ para a formação, em todos os níveis e modalidades de ensino e formação inicial e/ou continuada, acontece com a promulgação da Lei de Diretrizes e Bases da Educação (LDBEN N 9394/96), no artigo 80, alterado pelo Decreto $\mathrm{N}^{\circ} 9057 / 2017$ que amplia a expansão dessa modalidade (BRASIL, 1996; 2017), enquanto o acesso da população aos aparelhos celulares, tablets, notebooks e desktops e dos seus respectivos sistemas, android e/ou IOS e a World Wide Web, vem como facilitador do acesso ao conhecimento formal com o uso das Tecnologias Digitais de Informação e Comunicação (TDIC).

Ainda que se evidencie resistência à $\mathrm{EaD}$, esta se apresenta de extrema relevância no resgate à dignidade daqueles que por algum motivo ausentaram-se da sala de aula regular e foram colocados à margem da educação, amplia a possibilidade de cursar não apenas a Educação Básica como também o ensino superior, supera as dificuldades espaço-geográfica uma vez que é possível estudar em sua própria residência ou local de fácil acesso a internet, com flexibilidade nos horários de estudos, configurando-a como importante instrumento para atingir grandes contingentes populacionais e a possibilidade de acesso à educação formal enquanto direito fundamental do cidadão, numa sociedade democrática.

O uso das TDIC auxilia e facilita o processo de compreensão dos conteúdos, requer conhecimentos básicos para o manuseio por parte dos acadêmicos e docentes e podem servir de subsídios para o aprofundamento do conhecimento, assim como, fortalecer a troca de saberes entre discentes e docentes (KENSKI, 2012). Neste novo contexto o professor assume o papel de mediador no processo de construção do conhecimento, pode atender simultaneamente a vários estudantes em um espaço que não se restringe aos limites físicos da sala de aula regular e precisa aprender a trabalhar com variadas tecnologias que vão das mais simples as mais sofisticadas (PIMENTA; ANASTASIOU, 2002).

\section{AMBIENTE VIRTUAL D APRENDIZAGEM (AVA) E O PROFESSOR}

Seidler (2015) diz que a EaD favorece a modificação da organização do 'espaço' pedagógico onde as 'aulas' passam a ser as lições contidas no material didático, oferecendo maior flexibilidade para que cada aluno planeje os seus horários de estudos, respeitando as suas próprias necessidades, ritmos e estilo pessoal de leitura e 
aprendizagem. Essa modificação acontece no AVA onde são/estão disponibilizados os recursos elaborados para dinamizar, promover a cooperação e interação entre acadêmicos e equipe multiprofissional - coordenadores, tutores, técnicos em informática e comunicação, o professor-orientador - que buscam a análise coletiva, produções em equipes, fazendo com que o estudante exerça o papel de pesquisador (HACK, 2011).

O AVA, cujo suporte está na web, traduz as inúmeras vantagens que a rede de alcance mundial traz para a sociedade, uma vez que diversas instituições de ensino públicas ou particulares contribuem para que as políticas públicas se efetivem e façam acontecer a democratização da educação no Brasil utilizando essa metodologia de ensino na EaD (ARRUDA; ARRUDA, 2015).

O professor é o profissional que media, contribui no processo ensinoaprendizagem do acadêmico e o acompanha desde seus primeiros ingressos no AVA, torna-se o orientador e acompanha o acadêmico até a conclusão do curso com a produção científica final denominada TCC. Essa realidade tem possibilitado uma mudança de paradigma no processo de orientação dessa escrita, outrora caracterizado como um processo solitário de pesquisa e produção acadêmica.

A elaboração do TCC a distância, mediado pelo uso das TDIC que permite a interação orientador-orientando, conquista nova dimensão, rompe com a verticalidade da relação entre estes dois protagonistas, além de facilitar o registro do feedback e das orientações do professor-orientador, bem como de todo processo de construção do trabalho, por meio do histórico das diversas versões construídas e compartilhadas pelo ambiente virtual (KENSKI, 2012).

\section{ORIENTAÇÃO DE TRABALHO DE CONCLUSÃO DE CURSO NA EDUCAÇÃO A DISTÂNCIA}

Desde o primeiro semestre letivo deve haver orientação e conscientização junto aos acadêmicos para compreender que a elaboração do TCC não deve ser algo que demarque o fim próximo, mas que perpassa toda a vivência acadêmica, é um constructo contínuo e todos os esforços, pesquisas e estudos no âmbito de cada disciplina devem convergir para a construção paulatina do mesmo (SILVA; SIHLER, 2012).

O TCC é condição para a conclusão de cursos de graduação e/ou pós-graduação, sendo a culminância das investigações realizadas ao longo da vida acadêmica, em que o estudante aprofunda a reflexão sobre a sua formação, observados os procedimentos 
científico-metodológicos, a coerência entre seus elementos constitutivos, a sistematização teórico-prática, o estudo de um tema específico e principalmente a nãoprática do plágio, procedimento de cópia de ideias e textos de propriedade de outros autores como própria, reconhecido no Brasil como crime.

Nesse sentido, Almeida (2012) destaca sua preocupação perante a grande oferta de cursos EAD sem desenvolvimento de método científico com rigor metodológico. Essas preocupações se materializam no processo de orientação do TCC, prática vinculada ao PPC, integrando ensino, pesquisa e extensão, um desafio presente nos diferentes níveis de ensino realizados na $\mathrm{EaD}$ que requerem a pesquisa final, o que evoca a necessidade de refletir sobre o gerenciamento desse processo.

A orientação de TCC na modalidade EaD não é, reitere-se, tarefa isolada, envolve equipe multidisciplinar, apresenta desafios de diversas demandas como, por exemplo, a comunicação virtual que, por vezes, não são verificados na orientação presencial (SOUZA, 2015) e que podem ser minimizados pelo uso das TDIC que ampliam as possibilidades de interação entre as pessoas assim como o acesso a conteúdos digitais dentro e fora da $\mathrm{EaD}$, potencializando a mediação didáticopedagógica a distância (LITTO; FORMIGA, 2009).

Na orientação do TCC é essencial pensar no diálogo como mediador da relação pedagógica, compreender o orientando como sujeito autônomo, que constrói e se constrói subjetivamente, com suas relações, experiências, responsabilidades e liberdade, no processo pedagógico de construção da escrita científica, aproximando-se do pensamento freireano em que o diálogo é fundamental no processo e os educandos são os protagonistas do ensino-aprendizagem, devendo ter consciência, participação ativa do mesmo modo que deve ocorrer na educação à distância, colaborativa e interativa ao mesmo tempo (FREIRE, 1997; 2011; PITANO; GHIGGI, 2009).

\section{A PEDAGOGIA DA AUTONOMIA DE PAULO FREIRE}

Paulo Freire é reconhecido nacionalmente como Patrono da Educação Brasileira a partir da Lei N. 12.612/2012. Seu trabalho é notório por desenvolver ações de formação do sujeito pautado em uma proposta didático-metodológica, o Método Paulo Freire, utilizando-se de temas geradores, aplicado com cortadores de cana na cidade de Angicos (Pernambuco) no processo de alfabetização e emancipação daqueles na luta por melhores condições de trabalho e de vida, por isso a ideia da autonomia e da liberdade. 
Sua Pedagogia da Autonomia parte da ideia de que o sujeito é capaz de transformar a si e ao mundo quando de sua inserção no mundo cultural e letrado, um dos pilares de seus pressupostos teóricos. Sua proposta centra-se em uma educação para a libertação a partir das vivências e experiências do sujeito, mediadas no processo ensino-aprendizagem não como algo distante e sem sentido, antes, propõe que os ensinamentos estejam diretamente relacionados com o cotidiano do aprendente (FREIRE, 2002; CHIARELLA et al., 2014).

Na sua obra Pedagogia da Autonomia Paulo Freire faz necessária alusão ao fato de que quem está sendo formado, e neste caso específico, o acadêmico deve perceber-se como sujeito no processo de formação e não o objeto do formador, dando ênfase a não reprodução da educação bancária, prática pedagógica onde o aprendente apenas funciona como um depósito de informações sem conseguir refletir sobre as implicações daquelas em sua vida, a quem o autor tinha completo embate teórico-discursivo (FREIRE, 2002).

É possível inferir a partir do escrito de Freire (2002) que a relação que persiste no formador como sujeito e o formando seu objeto não põe abaixo a opressão do ser humano, antes mantém a relação de poder e de domínio de uma classe sobre a outra, reitera em sua célebre frase que "Quem ensina aprende ao ensinar e quem aprende ensina ao aprender." (FREIRE, 2002, p. 12) a partir das diferenças entre os dois protagonistas.

Nesta perspectiva, a Pedagogia da Autonomia traz importante aporte teórico para responder as perguntas de pesquisa e enaltecer na análise do corpus que a relação e atuação orientador-orientando deve ser horizontal para que o processo não seja desenvolvido por um apenas, mas que não havendo relações hierárquicas, sejam maiores as probabilidades de um produto acadêmico final melhor. Nesta mesma óptica.

\section{PERCURSO METODOLÓGICO}

Este se trata de estudo de abordagem qualitativa, dispensa quantidades fixas, redução às variáveis quantificadoras, valoriza a qualidade dos dados e informações (MINAYO, 2012); do tipo descritivo por buscar descreve uma realidade tal como esta se apresenta, usando a observação, o registro e a análise dos fenômenos (variáveis) (PRODANOV; FREITAS, 2013); e estudo de caso que propicia estudar a fundo um ou mais objetos, detalhando as informações, promover a compreensão da correlação entre 
o fenômeno, o ambiente e objeto. (SAMPIERI; COLLADO; LÚCIO, 2013).

O universo da pesquisa é uma Instituição de Ensino Superior (IES) da zona norte do Estado do Ceará, Instituição A, que iniciou no ano de 1999 com apenas o curso de Teologia presencial e hoje oferece graduações em diversas áreas do conhecimento, sendo a primeira instituição genuína do local a oferecer cursos próprios na modalidade EaD.

O lócus da pesquisa é o curso de Pedagogia EaD da instituição que tem idade próxima de 4 anos na data deste estudo, construído paulatinamente, hoje o curso que mais concentra acadêmicos na modalidade EaD. Conta com um corpo técnicopedagógico composto por 5 professores, também orientadores sendo um destes o Gestor de Estágio Supervisionado e Trabalho de Conclusão de Curso. Por ser um estudo de caso, o lócus é o próprio participante que atendeu como critério de inclusão ser o curso com maior concentração de acadêmicos na modalidade $\mathrm{EaD}$ e ter turmas em processo de construção do Trabalho de Conclusão de Curso.

A coleta de dados se deu de julho de2017 a janeiro de 2018 em dois momentos: $1^{\mathrm{o}}$ - acesso ao Projeto Pedagógico de Curso (PPC) para compreender a estrutura e funcionamento do TCC; $2^{\circ}$ momento: acesso ao AVA para verificar os registros de comunicação entre orientador e orientando. O corpus da análise foram o texto constante do PPC do Curso de Pedagogia EaD e o AVA sendo verificado neste o perfil das turmas de TCC (localização geográfica, gênero e grau de formação) e desenvoltura com o sistema, mensagens enviadas aos fóruns virtuais tira-dúvidas com suas angústias e percepções sobre pesquisa pelos orientandos, a forma comunicativa entre orientador e orientando e o perfil do orientador.

Os dados coletados foram tratados buscando se extrair os elementos que contemplassem a pergunta norteadora a partir do corpus, analisados com a Análise Temática de Minayo (2012) que e dividida em três etapas: pré-análise, exploração do material e tratamento do material, sendo apontadas quatro temáticas: Descrição do TCC no PPC do Curso de Pedagogia EaD, Perfil da turma de TCC do Curso de Pedagogia $\mathrm{EaD}$; A prática em pesquisas acadêmico-científicas; e o Perfil do orientador.

Uma vez tratados, a essência dos dados é apresentada de forma descritiva com análise crítico-reflexiva baseada na Pedagogia da Autonomia de Paulo Freire (1996) cujo princípio primordial é a autonomia do discente na construção de seu conhecimento, fugindo da ideia da Pedagogia Bancária onde o professor é o único detentor do conhecimento e o orientando se configura, apenas, como o bancário assim como da literatura pertinente. 
Em respeito aos preceitos éticos apontados na Resolução 510/2016 (BRASIL, 2016) que versa na preservação da imagem dos participantes de pesquisas se mantém o sigilo e a idoneidade da instituição participante prezando pelos princípios da beneficência e não maleficência bem como não expondo nem na íntegra, nem em textos os transcritos dos orientandos, mas fazendo menção indireta ao assunto.

\section{RESULTADOS E DISCUSSÃO}

A orientação do Trabalho de Conclusão de Curso é um processo lento e delicado que deve envolver todo o percurso da graduação, não deve ser pontual, tão menos deve representar um martírio para o acadêmico, entretanto seria demagogia pensar que na EaD ele estaria incólume a ser malvisto e até indesejado pelos concludentes.

Nesta perspectiva convém refletir sobre alguns apontamentos que inspiram maior cuidado nesta etapa de forma a colaborar com o acadêmico. Serão elencadas abaixo quatro temáticas que serão sequencialmente discutidas de forma a relacionar os cenários da pesquisa de TCC do acadêmico e o docente. Opta-se por esse formato por compreender que a reflexão deve partir do macro para o micro e vice-versa traçando indiretamente o perfil do acadêmico assim como do docente, do percurso entre o emissor e o receptor da mensagem.

\section{DESCRIÇÃO DO TRABALHO DE CONCLUSÃO DE CURSO DO PROJETO PEDAGÓGICO DE CURSO (PPC) DA IES}

O TCC no PPC do Curso de Pedagogia EaD da IES participante deste estudo pertence ao Núcleo de Estudos Integradores (NUEI), com carga horária total de 120 horas sendo 60h o TCC I e 60h TCC II e junto com outras disciplinas do mesmo núcleo tem como objetivo proporcionar que o acadêmico assuma a discussão dos conteúdos estudados contextualizando a sua prática ou a sua realidade, desenvolvendo sua autonomia, pois esta, segundo Freire (1996) é um processo dialético, subjetivo e individual, que depende das relações interpessoais desenvolvidas no espaço vivencial.

Presente nos dois últimos semestres do curso assume o mesmo caráter e estrutura dos demais cursos presenciais e/ou a distância da instituição. No TCC I o acadêmico deve desenvolver o Projeto de Pesquisa, validado pela sua qualificação mediante banca avaliadora composta por três membros, composto por temática de 
estudos, justificativa, relevância e quais as questões problema foram levantadas pelo estudo. O TCC II deve dar continuidade a proposta anterior e culminar, segundo as normas institucionais, em um trabalho monográfico seguindo as Normas Técnicas da Associação Brasileira de Normas Técnicas.

Pontue-se aqui que a IES não é a única a adotar tal norma, mas a produção monográfica, ao invés do artigo, como ocorre em outras instituições, e sua densidade de discussão e de páginas traz certo temor ao orientando. Deriva desta norma institucional o primeiro entrave quanto ao TCC, pois sempre de suas possibilidades, os orientandos conclamam a não existência da produção de final de curso.

A prerrogativa de exigência do TCC como condição para a conclusão de curso se ampara no Art. 207 da Constituição Federal de 1988 (BRASIL, 2017) que dá as IES autonomia didático-científica de forma a integrar pesquisa-ensino-extensão, o tripé do ensino superior, articulado nesta produção técnico-científico, reforçada pelos Pareceres 146/02 (BRASIL, 2002) e Parecer 0134/03 (BRASIL, 2003) que instituíam a obrigatoriedade do TCC, não sendo esta obrigatoriedade presente nas Diretrizes Curriculares Nacionais Para o Curso de Pedagogia aprovadas em 2006.

Há certa dificuldade por parte dos acadêmicos em compreender a produção de conclusão de curso na perspectiva do eu crítico-reflexivo e que tenha autonomia para, a partir de leituras e interpretações, construir suas concepções e opiniões, livres dos saberes instituídos e transmitidos exclusivamente pelo professor como se e somente se esse fosse o único a conhecer, rompendo por si próprios os preceitos da educação bancária onde somente o que é apresentado pelo professor é correto (FREIRE, 2002). Esta ruptura acaba por demandar outro entrave que é o perfil do acadêmico da graduação em $\mathrm{EaD}$.

\section{ANÁLISE DESCRITIVA DO PERFIL DAS TURMAS DE TCC EM PEDAGOGIA DA IES}

$\mathrm{O}$ curso de Pedagogia $\mathrm{EaD}$ da instituição participante tem regularmente matriculados 46 acadêmicos sendo 40 (89\%) mulheres e 6 (11\%) homens distribuídos nas Regiões Nordeste, 45 (99\%) e Região Sul 1 (1\%). Destes todos estão em suas primeiras licenciaturas, 43 (94\%) já são profissionais da Educação Infantil e/ou dos Anos Iniciais do Ensino Fundamental enquanto 1 (2\%) atua em outras áreas a citar o serviço de fiscalização do trânsito e 2 (4\%) não atuam na educação formal. 
Há, neste estudo, predomínio do sexo feminino a exemplo do estudo de Gomes, Mota e Leonardo (2014), Martins et al (2012), ambos realizados em Minas Gerais e dos dados do Censo EaD.br em sua sequência histórica dos anos de 2013 a 2016 (ABED, 2013; 2014; 2015; 2017) com mais da metade das matrículas sendo realizadas pelo sexo feminino, apesar de que esse predomínio não garante hegemonia do gênero feminino, mas é realidade dos cursos de Pedagogia, que apresentam as mulheres como responsáveis pelas matrículas na série histórica de 2009-2012 em todo o Brasil (ASSUMPÇÃO, 2014) ou ainda quanto a feminização de algumas profissões conforme Vianna (2013).

Os diálogos entre professor-orientador e orientandos, registrado em sistema, transparecem as dificuldade que alguns acadêmicos ainda têm quanto ao trato com o Ambiente Virtual de Aprendizagem (AVA). São questionamentos que expõem o não saber onde e/ou como fazer upload de documentos, atividades, pesquisas na internet, desconhecer os potenciais ou até mesmo do manuseio de outras ferramentas de pesquisa do tipo fazer uma busca bibliográfica, juntar documentos em um único, transformar documentos de word em pdf dentre outras situações que aos olhos de quem tem domínios de informática parecem banais.

A fragilidade no domínio da TDIC, identificada nas interações virtuais é consoante ao que já aponta o estudo de Godoi e Oliveira (2016), geralmente relacionada a ser o primeiro curso em $\mathrm{EaD}$, logo ser uma novidade para os mesmo de acordo com as considerações de Martins et al., (2013), podendo ser esta um fator que impacte positiva ou negativamente o desempenho do estudante de $\mathrm{EaD}$ (FIUZA, 2012), ratificado pelas considerações de Siluk, Silva e Dalcin (2016) realizado com os estudantes de um instituto federal na cidade de Farroupilhas onde $61 \%$ dos acadêmicos na modalidade $\mathrm{EaD}$ reconhecem suas poucas ou nenhuma habilidade para o manejo das tecnologias.

Ainda com a evolução das tecnologias e o acesso à rede mundial de computadores pelos diversos estratos sociais tais fatores não podem ser considerados post factum para que todos tenham desenvolvido aproximações com o uso das TDIC, implicando em certa dependência da figura do orientador, não se compreendem autônomos, buscando irromper com a ideia de ser o objeto na construção do conhecimento e sim sujeito que constrói ativamente seu processo ensino aprendizagem, questionando, sugerindo, opinando, tendo autonomia na escrita, pressupostos da Pedagogia da Autonomia (FREIRE, 2002; PINHEIRO et al., (2013).

Esta restrição está, geralmente, associada a uso das redes sociais Facebook, 
Instagram, Whatsapp dentre outras, mas com pouco acesso a textos acadêmicocientíficos ou pelo menos leituras mais interativas haja vista haver, hoje, uma gama de $e$ books, artigos de diversos estilos e formatos disponíveis o que, ainda que se seja acadêmico, tem pouca procura, salvo quando se tem uma obrigação de desenvolver atividades que requeiram pesquisas na rede e isso pode ter reflexos na produção do TCC.

\section{A PRÁTICA EM PESQUISAS ACADÊMICO-CIENTÍFICAS}

Antes o ingresso na vida acadêmica demarcava a transição da adolescência, saída do Ensino Médio para a vida adulta, responsável por marcar e demarcar profundas mudanças na forma de ver, perceber e interpretar os fenômenos, de assumir as responsabilidades da vida, de decidir o que fazer e como planejar seu futuro desde aquele momento. Esta ideia assume contornos com o advento da $\mathrm{EaD}$, a possibilidade de realização de cursos em qualquer faixa etária e nível de ensino à exceção da PósGraduação Stricto Sensu, o gerenciamento dos horários de estudos e a dinâmica de acesso no conforto do lar.

As condições que rompem com o espaço tempo-geográfico podem favorecer o distanciamento dos acadêmicos aos eventos acadêmicos-científicos como grupos de estudos e de pesquisa, monitoria voluntária, congressos, simpósios, mesas redondas e outros diversos, podendo repercutir na da escrita do TCC bem com na formação profissional uma vez que participar destes eventos proporcionam o contato com o planejamento, a pesquisa, a leitura, e consequentemente a escrita acadêmica, ampliam a percepção discente sobre os fenômenos que os cercam, contribuem para a construção da criticidade e da autonomia a partir de sua experiência formando-formador com o outro nos diálogos discursivos a partir das realidades (FREIRE, 2002).

Os achados de Bussolotti et al. (2016), Jesus et al. (2015) apontam que a maioria expressiva dos participantes de seus estudos concordam que as Atividades Complementares e as Atividades de Extensão contribuem substancialmente para suas evoluções acadêmicas e técnico-científicas enquanto o estudo de Figueiredo et al. (2016) ratificam a importância da participação em eventos científicos para a formação na academia.

Uma vez dentro da universidade, o caminhar efetivamente não deve se distanciar desse cuidado com a produção acadêmica, visto que é naquele espaço e com o incentivo de professores-orientadores que se tem a oportunidade de 'mergulhar', de ter contato com o mundo científico, da redação científica e consequentemente as 
contribuições da pesquisa para a preparação, aprimoramento e crescimento pessoal. A responsabilidade e autonomia do caminhar enquanto e pelo acadêmico da $\mathrm{EaD}$ não encontra eco no estudo de Pinheiro et al. (2013) que identificou dificuldades relacionadas as leituras dentro da modalidade $\mathrm{EaD}$ quando é importante a sua consciência de que seu caminhar independe exclusivamente do orientador.

Concorre-se com a concepção de Campos, Santos e Pinto e Santos (2009) que revelam haver confusão por parte dos participantes de seu estudo em compreender as contribuições da pesquisa e extensão, relacionando/atribuindo como favorável a produção de projetos de pesquisa, todavia não se pode deixar de contemplar que a participação em eventos favorece para o amadurecimento acadêmico a partir do contato direto com os textos produzidos cientificamente, possibilita o acesso a orientações de como desenvolver projetos de pesquisa e extensão sendo este um dos primeiros passos para a produção monográfica.

O aprofundamento nas leituras traz significativas e importantes contribuições na construção do ser ativo e responsável por modificar o ambiente onde está inserido, de forma crítico-reflexiva e autônoma como preceitua a Pedagogia da Autonomia de Paulo Freire (2002). Entretanto a forma como o acadêmico de graduação vê o TCC pode denunciar diversas nuances sobre os contatos iniciais e prévios entre estes, assumindo a visibilidade de reprovador e como consequência a perda de longos anos de estudos, a partir do tratamento dado a esse por outras experiências, a incerteza de sobre o que escrever, a pouca experiência no delineamento do objeto do estudo até o plágio, uma das mais severas características dos campos de produção científica.

O plágio por sua vez denuncia a fragilidade nos caminhos da pesquisa durante os anos vividos na graduação, a notória ilusão de que é possível produzir um engodo baseado nos recortes de fragmentos textuais e se configura como um dos principais problemas encontrados logo no TCC I, na análise dos projetos de pesquisa quando pela inexperiência, a quase não vivência da fase científica ou até mesmo amedrontado e pressionado entre a parede do ter que fazer e o não saber o que fazer o acadêmico opta por plagiar.

A prática do plágio é um problema encontrado no estudo doutoral de Vieira (2011) quando nos seus relatos reitera que os orientandos nem se quer sabem a definição de plágio, tão menos como é feito, principalmente pelo fato de pagar para a construção do material de conclusão de curso, realidade não distante na instituição lócus desse estudo quando os orientandos articulam, inclusive, o serviço de ouvidoria após a devolutiva do 
material identificado com o plágio, pelo orientador, para que seja reconstruído.

A distância espaço-geográfica vivenciada pela $\mathrm{EaD}$, no momento do TCC, parece ser um forte entrave tanto para o acadêmico quanto para o professor-orientador e requer dos dois atores importantes retomadas na forma como visualiza esta produção. Não se trata de abordar a produção do TCC como um processo solitário como aponta Costa e Silva e Silva (2012), Melo e Campo (2018) abreviado pela presença das novas tecnologias, mas está no cerne da própria dimensão compreendedora das informações transmitidas pelos orientadores e principalmente aceitar que todo texto é/está passível a mudanças.

A literatura em Souza (2015), Machado, Dominguini e Kahl (2014), Machado et al (2014) e Andrade (2011) identificam de forma equânime em seus resultados de estudos que um dos entraves está nas habilidades dos orientandos de manuseio das tecnologias, a ausência efetiva dos mesmos no ambiente virtual, a dificuldade de escrita acadêmica e o retorno dado ao feedback apontado na correção pelo orientador.

Ainda que os dados apontados por esses estudos sejam enfáticos é de suma importância fazer inferência ao papel desenvolvido pelo orientador em diversos aspectos como formação, dinâmica de comunicação, empatia e habilidades na comunicação com os orientandos uma vez que a sincronia pode ou não ocorrer em função de seus tempos de contatos, sobremaneira pelo fato de que os acadêmicos que fazem $\mathrm{EaD}$ quase sempre o fazem por melhor adequação entre seu tempo de estudos e de trabalho.

\section{O PERFIL DO PROFESSOR-ORIENTADOR}

Desde outrora o processo de orientação colocou o professor-orientador como centro no processo de produção do Trabalho de Conclusão de Curso, detentor de todo o saber a quem o orientando deveria total obediência nas leituras indicadas por aquele, ainda que não fosse uma leitura agradável ao orientando e não menos difícil é encontrar, ainda, profissionais que tomam esse momento como uma forma de demonstrar ao orientando que este não tem, ainda, conhecimentos o suficiente para uma escrita de qualidade.

Nesta perspectiva o profissional-orientador burla o que Freire (1996) aponta como sendo uma das premissas para a autonomia do sujeito:

Nesta forma de compreender e de viver o processo formador, eu, objeto agora, terei a possibilidade, amanhã, de me tornar o falso sujeito da "formação" do futuro objeto de meu ato formador. É preciso que, pelo contrário, desde os começos do processo, vá ficando cada vez mais claro que, embora diferentes entre si, quem forma se forma e re-forma 
ao formar e quem é formado forma-se e forma ao ser formado. (FREIRE, 1996, p. 12).

$\mathrm{Na}$ perspectiva da autonomia discente o orientador da EaD precisa compreender que suas habilidades não podem se restringir ao modelo presencial caso este tenha essa realidade e que seu perfil está atrelado a boa comunicação com seus orientandos de forma a contribuir para a construção da autonomia propalada por Freire em suas obras o que vai requerer do orientando disponibilidades para assumir seu espaço durante a produção que repita-se não deve ser solitária.

Estas características são devidamente elencadas nos estudos de Costa e Silva e Silva (2012) que identificam o espaço de feedback das análises como favoráveis a retomada quando surgirem dúvidas e/ou novos apontamentos o que pode se diferenciar do ensino presencial onde a comunicação oral por vezes é esquecida antes mesmo de retomar o material.

Souza (2015) ratifica que tão importante quanto as habilidades de comunicação está a aproximação do orientador com as ferramentas que são disponibilizadas, mas não apenas estas como a constante reflexão, a práxis pedagógica. Segundo Freire (2011), esta práxis é o momento em que a teoria e prática se unem na ação ativa e libertadora, sempre mediada pela dialogicidade como método e pela horizontalidade como parte do ser. Em que o sujeito participa da construção de uma história em que ele figure como protagonista, de maneira a batalhar em prol de uma sociedade sem dominantes e dominados.

$\mathrm{O}$ orientador que porventura venha da modalidade presencial, o processo na EaD demanda uma nova formação de opinião, de concepção e consequentemente requer uma nova prática, livre dos moldes bancários que fazem do conhecimento apenas um processo depositário (FREIRE, 1996).

É inegável que há considerável necessidade de adequação temporal por parte dos educandos, conforme já apontam Machado et al., (2014), e a produção do TCC não pode ser vista como o martírio da conclusão de seu curso, mas que este deve abrir espaço para a construção de uma nova consciência sobre o assunto ali abordado, discutido, entendendo que esta escrita é um legado, um contributo às ciências e a produção formal do conhecimento, um produto inacabado que sempre poderá ser retomado.

É na busca pelos textos adequados, na decisão de qual percurso metodológico mais se adequa à pesquisa, quais objetivos vem à mente e como todo o processo será contextualizado, quais os instrumentos mais adequados à pesquisa que a díade 
orientador-orientando contempla a autonomia proclamada em Freire (1996), necessária em face da realidade dos números de orientandos, geralmente agigantados, que um orientador terá/tem/teve na Educação a Distância.

Seria utópico omitir que a pouca experiência do orientador no trato com a orientação e de modo particular com a Educação a Distância não se configura como um entrave, entretanto a perspectiva se sobrepõe aos mesmos se forem consideradas todas as possibilidades de formação desse próprio profissional professor. Quando se vivencia a experiência de ser orientado na modalidade $\mathrm{EaD}$ se consegue sentir e perceber melhor os anseios e as angústias daqueles que são orientados, o que pode melhorar a relação de empatia entre estes.

\section{CONSIDERAÇÕES FINAIS}

As limitações são inerentes a qualquer estudo, de qualquer área. Neste a escassez na literatura voltada para a temática específica da orientação na Educação a Distância se configurou como preponderante, uma vez que os textos publicados em periódicos quase sempre estão voltados à orientação de TCC presencial, estando esta temática mais presente em eventos científicos.

É inegável que o trabalho de conclusão de curso jamais demandará o grau de amadurecimento do acadêmico, que a realização do TCC definitivamente determinará um pesquisador nato, mas a produção deste constitui como fonte de produção inicial dos conhecimentos científicos formais e por esse fato devem ser produzidos considerando-se o mínimo dos parâmetros apontados pelas normas da Associação Brasileira de Normas Técnicas (ABNT), mas não apenas essas, mas tendo coesão e coerência entre os elementos que encadeiam o texto.

A faculdade do trabalho de conclusão de curso nos Projetos Políticos de Curso tem se tornado mais factual, sobremaneira pela após a legislação que faculta sua obrigatoriedade, mas se pondera, neste estudo, considerar que excluir o TCC da experiência acadêmica de um acadêmico não fará dele um profissional com melhores competências, mas indiscutivelmente omite deste a oportunidade de compreender os passos da pesquisa centrada no conhecimento científico, ao invés do senso comum e de forma especial quando estes profissionais são professores, que tem a missão de formar outros profissionais.

Ainda nesta mesma óptica há o precedente de que a faculdade acima descrita 
poderá estar formando um fosso a ser superado sob quaisquer circunstâncias quando da necessidade da produção do TCC na Pós-Graduação Lato Sensu, ou seja, se poupa o acadêmico na graduação, quando este está solidificando suas bases científicas e se cobra essas na especialização.

O professor-orientador-tutor por sua vez mantém a missão de manter-se mais humano que antes, compreendendo que a ausência dos encontros presenciais dificulta a percepção, pelo orientando, de sua afetividade no processo de construção do TCC, de forma especial quando do feedback, momento em que há o contato com a correção, ainda assim não se pode, nesta relação, omitir-se de cumprir os preceitos éticos e morais da pesquisa.

O TCC é realmente uma produção que demanda desgaste psicoemocional, que exige do orientando competências e habilidades para a pesquisa e seleção de materiais e principalmente a superação do senso comum para o senso crítico-reflexivo, faz-se mister compreender que ele também é humano que tem durante o processo de construção, uma vida com suas respectivas realidades e o orientador, também humano deve ter sensibilidade para compreender limites e limitações.

Não se pode tão menos se deve pensar em uma produção solitária, onde um dos autores toma para si o andamento enquanto o outro apenas delega, condena ou pontua mudanças, antes é importante compreender que frente aos entraves deve existir a expectativa de construção do conhecimento por ambos e assim a contribuição se efetiva e se torna robusta.

\section{REFERÊNCIAS}

ASSOCIAÇÃO BRASILEIRA DE EDUCAÇÃO A DISTÂNCIA. Censo EAD.BR: relatório analítico da aprendizagem a distância no Brasil 2013 = Censo EAD.BR: analytic report of distance learning in Brazil 2016 [livro eletrônico]. Traduzido por Thereza Moss de Abreu. Curitiba: Ibpex, 2014. Disponível em: http://www.abed.org.br/censoead2013/CENSO_EAD_2013_PORTUGUES.pdf. Acesso em: 30 de janeiro de 2018

Censo EAD.BR: relatório analítico da aprendizagem a distância no Brasil 2016 = Censo EAD.BR: analytic report of distance learning in Brazil 2014 [livro eletrônico]. Traduzido por Thereza Moss de Abreu. Curitiba: Ibpex, 2015. Disponível em: http://www.abed.org.br/censoead2014/CensoEAD2014 portugues.pdf. Acesso em: 30 de janeiro de 2018

Censo EAD.BR: relatório analítico da aprendizagem a distância no Brasil 2016 = Censo EAD.BR: analytic report of distance learning in Brazil 2016 [livro eletrônico]. Traduzido por Thereza Moss de Abreu. Curitiba: InterSaberes, 2017. 
Disponível em: http://abed.org.br/censoead2016/Censo EAD 2016 portugues.pdf. Acesso em: 30 de janeiro de 2018.

ANDRADE, Valter Zotto de. A comunicação entre o orientador de monografias e o orientando de pós-graduação nos ambientes virtuais de aprendizagem. In: Congresso Nacional de Educação - EDUCERE, X, 2011, Curitiba. Anais... Curitiba-PR, 2011. Disponível em: http://educere.bruc.com.br/CD2011/pdf/5601_3128.pdf. Acesso em: 29 de janeiro de 2018.

ARRUDA, Eucidio Pimenta; ARRUDA, Durcelina Ereni Pimenta. Educação à distância no brasil: políticas públicas e democratização do acesso ao ensino superior. Educação em Revista. Belo Horizonte, v.31, n.03,p. 321-338, Julho-Setembro, 2015. Disponível em: http://www.scielo.br/pdf/edur/v31n3/1982-6621-edur-31-03-00321.pdf Acesso em: 20 de janeiro de 2018.

ASSUMPÇÃO, Andreia dos Santos Barreto Monsores de. A mulher no Ensino Superior: distribuição e representatividade. Cadernos do GEA, n. 6, p. 7-48, jul./dez. 2016.

BRASIL. [Constituição (1988)]. Constituição da República Federativa do Brasil [recurso eletrônico]. Brasília: Supremo Tribunal Federal, Secretaria de Documentação, 2017.

Disponível em:http://www.stf.jus.br/arquivo/cms/legislacaoConstituicao/anexo/CF.pdf . Acesso em: 25 de janeiro de 2018.

. Casa Civil. Lei de Diretrizes e Bases da Educação Nacional. Estabelece as diretrizes e bases da educação nacional. Disponível em: https://www.planalto.gov.br/ccivil_03/LEIS/L9394.htm\#art80. Acesso em: 25 de agosto de 2018.

Casa Civil. Decreto $\mathbf{N}^{\circ}$ 9057, de 25 de maio de 2017. Regulamenta o art. 80 da Lei $N^{0}$. 9394, de 20 de dezembro de 1996, que estabelece as diretrizes e bases da educação nacional. Disponível em: https://www.planalto.gov.br/ccivil_03/_Ato20152018/2017/Decreto/D9057.htm\#art24. Acesso em: 25 de agosto de 2018.

Casa Civil. Decreto N. 9057 de 25 de maio de 2017. Regulamenta o art. 80 da Lei $n^{\circ}$ 9394, de 20 de dezembro de 1996, que estabelece as diretrizes e bases da educação nacional. Disponível em: http://www.planalto.gov.br/ccivil_03/_Ato20152018/2017/Decreto/D9057.htm. Acesso em 25 de agosto de 2018

BUSSOLOTTI, Juliana Marcondes et al. A importância das atividades complementares no processo de aprendizado: percepção dos alunos de cursos de educação a distância da universidade de Taubaté. In.: Congresso Internacional ABED de Educação a Distância, 22, 2016. Águas de Lindoia. Anais... Águas de Lindoia-SP, 2016. Disponível em: http://www.abed.org.br/congresso2016/trabalhos/137.pdf. Acesso em: 29 de janeiro de 2016.

CAMPOS, Fernando Guerra Grossi; SANTOS, Raquel Fontes; PINTO E SANTOS, Flávia Costa. A importância da pesquisa científica na formação profissional dos alunos do curso de Educação Física do UNILESTEMG. Movimentum - Revista Digital de Educação Física. Ipatinga, v. 4, n. 2, p. 1-11, ago./dez., 2009. Disponível em: https://www.unilestemg.br/movimentum/Artigos V4N2 em pdf/Campos Santos Sant os_Movimentum_v4_n.2_2_2009.pdf. Acesso em: 25 de janeiro de 2018.

CARVALHO, Adélia Honório de. A evolução histórica da educação a distância no Brasil: avanços e retrocessos. 2013. 36f. Monografia. (Especialização em Educação, Métodos e Técnicas de Ensino) - Universidade Tecnológica Federal do Paraná, 2013. 
Disponível

em:http://repositorio.roca.utfpr.edu.br/jspui/bitstream/1/4653/1/MD_EDUMTE_II_201

2 01.pdf. Acesso em: 31 de janeiro de 2018.

CHIARELLA, Tatiana et al., A Pedagogia de Paulo Freire e o processo ensinoaprendizagem na Educação Médica. Revista Brasileira de Educação Médica, Brasília, v. 39, n. 3, p. 418-425, 2015. Disponível em: http://www.scielo.br/pdf/rbem/v39n3/1981-5271-rbem-39-3-0418.pdf . Acesso em: 26 de agosto de 2018. http://dx.doi.org/10.1590/1981-52712015v39n3e02062014.

COSTA E SILVA, Ana Paula; SIHLER, Anelise Pereira; SILVA, Chris Alves da. Orientação de Trabalhos de Conclusão de Curso a distância: uma experiência fundamentada na interação. RENOTE. Rio Grande do Sul, v. 10, n. 1, p. 1-7, julho, 2012. Disponível em: http://seer.ufrgs.br/index.php/renote/article/view/30855/19211. Acesso em: 30 de janeiro de 2018.

FIGUEIREDO, Jucelir de Oliveira et al. A importância da participação dos estudantes do ensino superior em eventos científicos para sua formação acadêmica. In.: Congresso Nacional de Educação, III, 2016. João Pessoa-PB, 2016. Disponível em: https://editorarealize.com.br/revistas/conedu/trabalhos/TRABALHO_EV056_MD4_SA 4 ID2844 15082016151347.pdf. Acesso em: 29 de janeiro de 2018.

FREIRE, Paulo. Pedagogia da autonomia: saberes necessários à prática educativa. 13. ed. Rio de Janeiro: Paz e Terra, 1996. Disponível em:http://educadores.educacao.ba.gov.br/system/.../pdf-pedagogiadaautonomiapaulofreire.pdf. Acesso em 31 de janeiro de 2018.

FREIRE, Paulo. Educação como prática da liberdade. 14. ed. ver. atual. Rio de Janeiro: Paz e Terra, 2011.

DE GODOI, Mailson Alan. O Perfil do Aluno da Educação a Distância e seu Estilo de Aprendizagem. EaD em FOCO, [S.1.], v. 6, n. 2, ago. 2016. Disponível em: http://eademfoco.cecierj.edu.br/index.php/Revista/article/view/383/177. Acesso em: 31 de Janeiro 2018.

GOMES, Silvane Guimarães Silva; MOTA, João Batista; LEONARDO, Estela da Silva. Reflexão do perfil do aluno como determinante para a motivação e aprendizagem do curso de EaD. Cad. Ed. Tec. Soc. Inhumas, v. 7, p. 355-363, 2014. Disponível em: http://cadernosets.inhumas.ifg.edu.br/index.php/cadernosets/article/download/214/118. Acesso em: 30 de janeiro de 2018.

HACK, Josias Ricardo. Introdução à educação a distância. Florianópolis: LLV/CCE/UFSC, 2011.

JESUS, Daniele Oliveira de et al. Extensão e pesquisa na modalidade EaD: qual a realidade dos cursos de Administraçãode Vitória da Conquista-BA?. In.: Seminários de Administração, XVIII, 2015. São Paulo-SP, 2015. Disponível em: http://periodicos.uesb.br/index.php/sasb/article/viewFile/6104/5869. Acesso em: 28 de janeiro de 2018.

KENSKI, Vani Moreira. Educação e Tecnologias: o novo ritmo da informação. $8^{\mathrm{a}}$ ed. Campinas, SP: Papirus, 2012.

LITTO, Fredric; FORMIGA, Marcos (orgs). Educação a distância: o estado da arte. São Paulo: Pearson Education do Brasil, 2009.

MACHADO, Andreia de Bem et al. Comunicação na EaD: uma análise do processo de orientação de monografia. In.: Congresso Internacional ABED de Educação a Distância, 20, 2014. Florianópolis. Anais... Florianópolis-SC, 2014. Disponível em: 
http://www.abed.org.br/hotsite/20-ciaed/pt/anais/pdf/98.pdf. Acesso em: 28 de janeiro de 2018.

MACHADO, Andreia de Bem; DOMINGUINI, Lucas; KAHL, José Carlos. O pape do orientador de monografia da Educação à Distância. Travessias, v. 8, n. 02, $21^{\mathrm{a}}$ edição, p. 197-209, 2014. Disponível em: http://erevista.unioeste.br/index.php/travessias/article/download/8447/7828. Acesso em: 27 de janeiro de 2018.

MARTINS, Ronei Ximenes et al. O perfil sociodemográfico de candidatos a cursos de licenciatura a distância e os objetivos da Universidade Aberta do Brasil. In.: Congresso Brasileiro de Ensino Superior a Distância, IX, 2014. Recife. Anais... Recife-PB, 2014. Disponível em: http://www.dired.ufla.br/portal/wpcontent/uploads/2012/10/IXESUDat1-completoroneiludmilalucianamarina.pdf. Acesso em: 30 de janeiro de 2018.

MELO, Keite Silva de; CAMPOS, Gilda Helena Bernardino de. Trabalho de conclusão de curso: trabalho interativo na orientação em EAD. Momento - Diálogos em Educação, [S.1.], v. 27, n. 1, p. 282-299, maio, 2018. Disponível em: https://periodicos.furg.br/momento/article/view/7754/5244. Acesso em: 26 de agosto de 2018. DOI:https://doi.org/10.14295/momento.v27i1.7754.

MINAYO, Maria Cecília de Souza. Análise qualitativa: teoria, passos e fidedignidade. Ciênc. saúde coletiva, v. 17, n. 3, p. 621-626, 2012.

MORIN, Edgar. "Nosso pensamento está muito preso ao passado." Jornal O Estado de São Paulo. São Paulo, 02/08/2009, Suplemento cultura, p. 6-7.

PIMENTA, Selma Garrido; ANASTASIOU, Léa das Graças Camargo. Docência no ensino superior. São Paulo: Cortez, 2002.

PINHEIRO, Ana Lucia F. B et al. Percepções e dificuldades do aluno na disciplina Metodologia do Trabalho Científico na modalidade semipresencial. Revista Trilha Digital, São Paulo, v. 1, n. 1, p. 90-106, 2013. Disponível em: http://editorarevistas.mackenzie.br/index.php/TDig/article/view/5889/4251. Acesso em 26 de agosto de 2018.

PITANO, Sandro de Castro; GHIGGI, Gomercindo. Autoridade e liberdade na práxis educativa Paulo Freire e o conceito de autonomia. SABERES, Natal-RN, v. 2, n. 3, p. 80-93. Disponível em: https://periodicos.ufrn.br/saberes/issue/view/71. Acesso em 26 de agosto de 2018.

PRODANOV, Cleber Cristiano; FREITAS, Ernani César. Métodos e Técnicas de Pesquisa e do Trabalho Acadêmico. 2. ed. Novo Hamburgo: Feevale, 2013.

SAMPIERI, Roberto Hernández; COLLADO, Carlos Fernandes; LUCIO, María del Pilar Baptista. Métodos de Pesquisa. 5.ed. Porto Alegre: Penso, 2013.

SEIDLER, Elaine Monteiro. Ferramenta de leitura dlnotes2: sua aplicabilidade na educação a distância (EAD). Disponível em: https://repositorio.ufsc.br/xmlui/bitstream/handle/123456789/136412/FERRAMENTA \%20DE\%20LEITURA\%20DLNOTES2_Elaine\%20Monteiro\%20Seidler.pdf?sequence $=1 \&$ is Allowed=y. Acesso em: 10 de janeiro de 2017.

SIGNORINI, Roney. Parecer 146/02 e sucedâneos. Disponível em: http://roneysignorini.com.br/pdf/Parecer\%20146.pdf. Acesso em 25 de janeiro de 2018.

SILUK, Ana Cláudia Pavão; SILVA, André Hellvig da; DALCIN, Eduardo. O aluno em foco na EaD: perfil e competências. In.: Simpósio Internacional de Educação a 
Distância. Encontro de Pesquisadores em Educação a Distância, 2016. São Carlos. Anais... São Carlos-SP, 2016. Disponível em: http://www.siedenped2016.ead.ufscar.br/ojs/index.php/2016/article/viewFile/1795/786. Acesso em 25 de janeiro de 2018

SOUZA, Roger Marchesini de Quadros. Os desafios do processo de construção do TCC em EaD. Educação e Linguagem, v. 18, n.2, p. 87-100, jul./dez., 2015. Disponível em: https://www.metodista.br/revistas/revistas-

ims/index.php/EL/article/viewFile/6630/5235. Acesso em: 28 de janeiro de 2018.

VIANNA, Claudia Pereira. A feminização do magistério na educação básica e os desafios para a prática e a identidade coletiva docente. In: YANNOULAS, Silvia Cristina (Org.). Trabalhadoras: análise da feminização das profissões e ocupações. Brasília, DF: Abaré, 2013. p. 159-180. Disponível em: http://www.producao.usp.br/handle/BDPI/44242. Acesso em: 29 de janeiro de 2018.

VIEIRA, Leocádia Aparecida. Entre o real e o virtual: a Educação a Distância (EaD) como espaço para o educar (aprender e ensinar) pela pesquisa. 198f. Tese (Doutorado em Educação) Pontifícia Universidade Católica de São Paulo, São Paulo, 2011. Disponível em: http://www4.pucsp.br/gepi/downloads/RESUMO DISSERTACOES GEPI/2011 TES E_LEOCILEA.pdf. Acesso: em 25 de agosto de 2018. 